\title{
Design of optimally safe recovery boilers against occurrence and consequences of internal explosions
}

\author{
H. Martikka ${ }^{1}$, I. Pöllänen ${ }^{2}$ \& J. Simonen ${ }^{3}$ \\ ${ }^{1}$ Department of Mechanical Engineering, \\ Lappeenranta University of Technology, Lappeenranta, Finland \\ ${ }^{2}$ SAV Oy Engineering, Finland \\ ${ }^{3}$ Andritz Ltd, Finland
}

\begin{abstract}
The objects of study are recovery boilers. They are essential parts in the paper processing industry for burning chemicals into a more ecological form and for obtaining steam. One goal in the design of recovery boilers is to reduce the risks and consequences of water to melt explosion and the risk of inflammable gas explosions. The walls are orthotropic tubular laminates. One method to reduce risk is to improve local geometry and welding. Another is to consider the total structure and vent out the pressure peaks of explosion to the outside.

Analytical optimum design methods using theory of orthotropic plates are used to obtain optimal ranges of main design variables and their physical effect on total reliability. The FEM program MSC Nastran is used to calculate in detail the elastic-plastic responses. The results show that damage risk can be minimised by redesigning critical joint areas and using optimally stiffeners.

Keywords: protection of structures, blast loads, composite shells.
\end{abstract}

\section{Introduction}

Recovery boilers are essential parts in paper processing industry for burning chemicals into more ecological form and for obtaining steam. One goal in design of recovery boilers is to consider risks and consequences of water to steam explosion and risk of inflammable gas explosion. Risk situations are controlled 
at annual shutdowns. Small leaks in tube welding and in thinned tubes can cause large pressure rise or blast. Plastic deformations occur and risks may increase.

Several approaches are used. One is to study in detail tubes and local welds. Analytical approach is to model walls as orthotropic plates using models in Agarwal and Broutman [1], Barbero [2] and Swanson [3]. Stresses can be obtained by connection relations. The FEM approach is used to give a detailed actual model for plate. Plastic deformations are obtainable by MSC Nastran [4] and fracturing to pieces using LS DYNA [5]. Gas explosion pressures can be modelled as shown by Kurttila [6]. The main purpose of this study is to present results of a damage analysis of a case study of an industrial recovery boiler.

\section{Materials and methods}

\subsection{Main structure of a recovery boiler}

The boiler structure is shown schematically in fig. 1.Some requirements are: 1 Leakage resistance at inner surfaces should be reliable for about 30 years.

2 Mechanical endurance should be cost-effectively optimum.

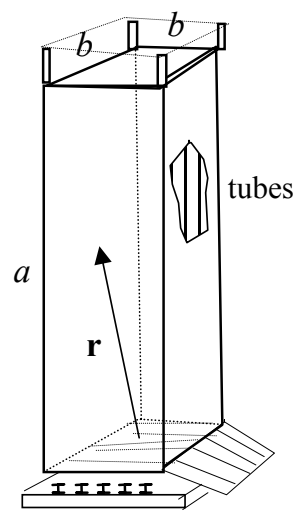

a)

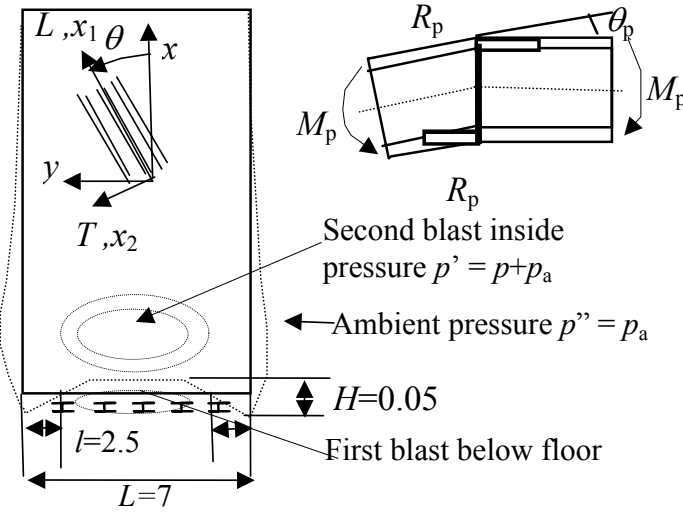

b)

c)

Figure 1: $\quad$ Sketch of main structure of a recovery boiler. a) Main dimensions height $a=32$, base $b=7 \mathrm{~m}$. b) Blast areas. c) Plastic bending of a bottom tube.

\subsection{Blast risks}

Due to leakage at bottom tubes an explosion occurs some times on the floor in the melt bed. When one $\mathrm{kg}$ of pressurised water at $300 \mathrm{C}$ explodes at $800 \mathrm{C}$ in the furnace an energy $E=600 \mathrm{~kJ} / \mathrm{kg}$ is released. Next an estimate for the mass $m$ of water is estimated using data of magnitude observed damages in a case study. Externally input energy balance gives 


$$
W_{\mathrm{e}, \text { water to gas }}=m E=m[\mathrm{~kg}] 0.6\left[\frac{\mathrm{MNm}}{\mathrm{kg}}\right]=W_{\mathrm{e}, \text { gas expansion }}=p V=p \cdot H l(L-l) .
$$

Gas expands to volume $V$ box with dimensions $H=0.005 \mathrm{~m}, l=2.5, L=7$.

Plastic bending work of $N=132$ tubes at $3 . .4$ places to an angle $\theta=H / l=0.05 / 2.5=0.02$ gives $W_{\mathrm{i}, \mathrm{pl}}$. Fully plastic bending moment of a tube of radius $r$ and wall $t$ and yield strength $R_{\mathrm{p}}=250 \mathrm{MPa}$ is

$$
M_{\mathrm{p}}=R p \cdot 1.274 \pi r^{2} t=250 \mathrm{MPa} \cdot \pi 0.024^{2} 0.0055=3000 \mathrm{Nm} .
$$

Average furnace mass load pressure $p_{\text {load }}=\rho g h$ resists the gas pressure $p$

$$
\begin{aligned}
& (p-\rho g h) V=W_{i, \text { plast }}=N i M_{\mathrm{p}} \theta=132 \cdot(3 . .4) \cdot 3000 \cdot 0.02 \approx 0.03 \mathrm{MNm} \\
& (p-0.006 \mathrm{MPa}) 1.52 \mathrm{~m}^{3} \approx 0.03 \mathrm{MNm}=m 0.6 \rightarrow p=0.02 \mathrm{MPa}, \quad m=0.05 \mathrm{~kg}
\end{aligned}
$$

\section{Boiler side wall strain and stress analysis}

The boiler wall can be modelled as an orthotropic plate.

\subsection{Orthotropic plate model}

Equation of state for a laminate structure is [1]

$$
\left[\begin{array}{l}
\mathbf{N} \\
\mathbf{M}
\end{array}\right]=\left[\begin{array}{ll}
\mathbf{A} & \mathbf{B} \\
\mathbf{B} & \mathbf{D}
\end{array}\right]\left[\begin{array}{l}
\varepsilon^{0} \\
\kappa
\end{array}\right] .
$$

Here $\mathbf{N}$ is line force and $\mathbf{M}$ is line moment stress resultants, $\varepsilon^{0}$ is midplane strain and $\kappa$ is curvature. The moments are now of interest and in detail [1],

$$
\left[\begin{array}{c}
M_{x} \\
M_{y} \\
M_{x y}
\end{array}\right]=\sum_{k=1}^{k=n} \int_{h_{\mathrm{k}-1}}^{h_{\mathrm{k}}}\left[\begin{array}{c}
\sigma_{x} \\
\sigma_{y} \\
\tau_{x y}
\end{array}\right]_{\mathrm{k}} \bullet z d z=\sum_{k=1}^{k=n} \int_{h_{\mathrm{k}-1}}^{h_{\mathrm{k}}} \sigma_{\mathrm{k}} \bullet z d z \cdot
$$

The stress is by Hooke's law

$$
\sigma=\bar{Q} \varepsilon=\bar{Q}\left(\varepsilon_{0}+z \kappa\right)=\bar{Q} \varepsilon_{0}+z \bar{Q} \kappa
$$

Now there is one plate or "laminate" and bottom and top surface co-ordinates from mid plane are $h_{\mathrm{k}-1}=-1 / 2 h$ and $h_{\mathrm{k}}=1 / 2 h$. This gives, [1],

$$
\left[D_{\mathrm{ij}}\right]=\frac{1}{3} \sum_{k=1}^{k=n}\left\langle\bar{Q}_{\mathrm{ij}}\right\rangle_{\mathrm{k}} \cdot\left(h_{\mathrm{k}}{ }^{3}-h_{\mathrm{k}-1}{ }^{3}\right)=\frac{h^{3}}{12}\left[\bar{Q}_{\mathrm{ij}}\right] \rightarrow D=I^{\prime} Q \quad, \quad I^{\prime}=\frac{h^{3}}{12} .
$$


If neutral plane strains are zero then the relationship between moment resultants, curvatures and stiffness properties is, [3],

Thus

$$
\left[\begin{array}{l}
M_{x} \\
M_{y} \\
M_{x y}
\end{array}\right]=\left[\begin{array}{lll}
D_{11} & D_{12} & D_{16} \\
D_{12} & D_{22} & D_{26} \\
D_{16} & D_{26} & D_{66}
\end{array}\right]\left[\begin{array}{c}
\kappa_{\mathrm{x}} \\
\kappa_{\mathrm{y}} \\
\kappa_{\mathrm{xy}}
\end{array}\right]=\frac{h^{3}}{12}\left[\begin{array}{ccc}
Q_{11} & Q_{12} & 0 \\
Q_{12} & Q_{22} & 0 \\
0 & 0 & Q_{66}
\end{array}\right]\left[\begin{array}{c}
\kappa_{\mathrm{x}} \\
\kappa_{\mathrm{y}} \\
\kappa_{\mathrm{xy}}
\end{array}\right] .
$$

$$
\mathbf{M}=I^{\prime} \mathbf{Q k} \rightarrow M_{\mathrm{y}}=I^{\prime}\left(Q_{12} \kappa_{\mathrm{x}}+Q_{22} \kappa_{\mathrm{y}}\right) \rightarrow I^{\prime} \Sigma D \kappa
$$

Bending stress is

$$
\sigma_{\mathrm{y}}=\frac{M_{\mathrm{y}}}{I^{\prime}} z=\frac{Q I^{\prime} \kappa}{I^{\prime}} z=Q \kappa z=\left(Q_{12} \kappa_{\mathrm{x}}+Q_{22} \kappa_{\mathrm{y}}\right) z
$$
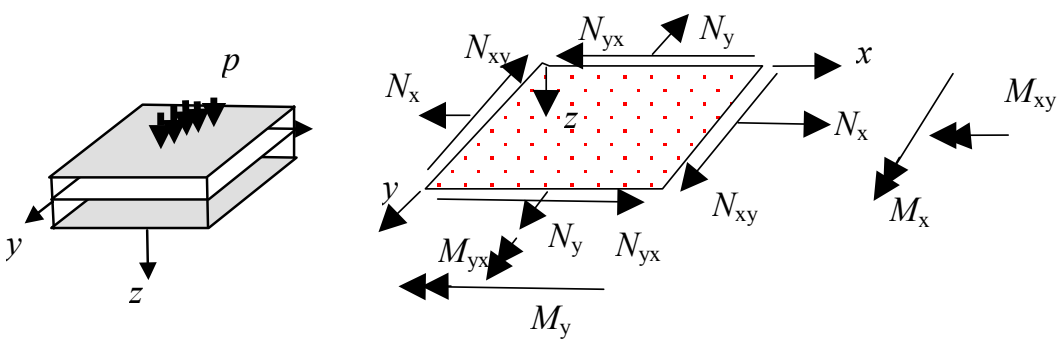

Figure 2: $\quad$ Plate deformation and stress resultant definitions.

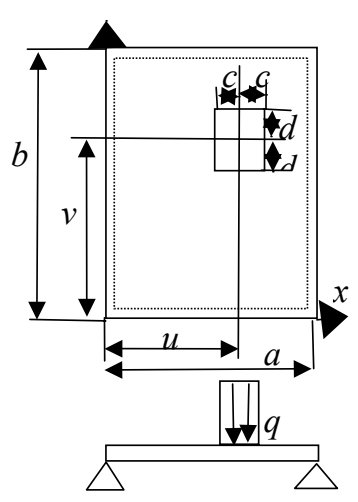

a)

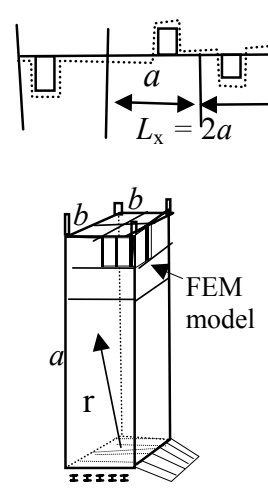

b)

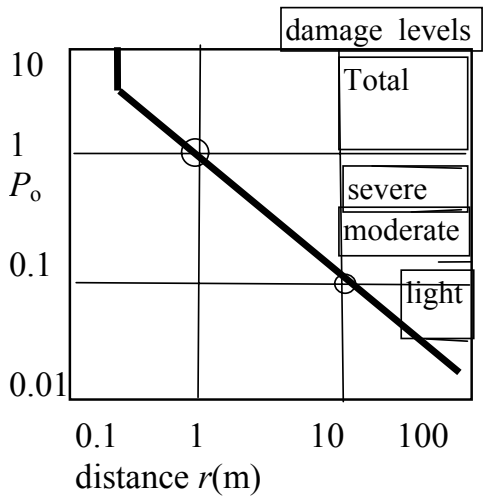

c)

Figure 3: a) Loading and support for a plate. b) Distance $r$ from explosion centre to plate and FEM model location. c) Relative overpressure vs. distance $r$ and damage levels according Kurttila [6, p.102]. 


\subsection{Loading and support models}

Loading is a pressure force impact on an area of the plate. It is a complex task to model with detailed dynamics. Therefore an equivalent static peak model was used. The simplifying assumptions require proving. First, in a large partly open volume the rise of pressure is relatively not very fast. Secondly, a point force model is used applied at the middle of the side plate gives a conservative result thirdly, if an even distribution was applied then pressure would 0.4 times the peak pressure. Kurttila [6] has studied an explosion accident of a steam accumulator with volume $10 \mathrm{~m}^{3}$, placed inside boiler housing. In Figure $3 \mathrm{c}$ an overpressure vs. distance from explosion is shown. The ambient pressure is $p_{\mathrm{a}}=0.1 \mathrm{MPa}$ and a pressure of $0.25 \mathrm{MPa}$ could be the burst pressure causing tensile failure if attained at the walls. At $P_{\mathrm{o}}=1$ at $r=1 \mathrm{~m}$ to $P_{\mathrm{o}}=0.1$ at $r=10 \mathrm{~m}$ is obtained. Thus at the present case this means that a burst level pressure will decrease by a factor of about 0.1 .

\subsection{Plate deformation models}

These are visualised in fig. 2. First in x-direction one obtains

$$
\begin{aligned}
& \gamma_{\mathrm{xz}}=\frac{\partial u}{\partial z}+\frac{\partial w}{\partial x} \neq 0 \rightarrow u=u_{0}-z\left(\frac{\partial w}{\partial x}-\gamma_{\mathrm{xz}}\right)=u_{0}+z\left(\gamma_{\mathrm{xz}}-\frac{\partial w}{\partial x}\right) \\
& u=u_{0}+z \alpha \quad, \quad \alpha=\gamma_{\mathrm{xz}}-\frac{\partial w}{\partial x}, \rightarrow \kappa_{\mathrm{x}}=\frac{\partial \alpha}{\partial x}=\frac{\partial}{\partial x}\left(\gamma_{\mathrm{xz}}-\frac{\partial w}{\partial x}\right)=\frac{\partial \gamma_{\mathrm{xz}}}{\partial x}-\frac{\partial^{2} w}{\partial x^{2}}
\end{aligned}
$$

Similarly in y - direction

Three equations for the orthotropic plate are according to Swanson [3].

$$
\begin{aligned}
& D_{11} \frac{\partial^{2} \alpha}{\partial x^{2}}+\left(D_{11}+D_{66}\right) \frac{\partial^{2} \beta}{\partial x \partial y}+D_{66} \frac{\partial^{2} \alpha}{\partial y^{2}}-A_{55}\left(\alpha+\frac{\partial w}{\partial x}\right)=0 \\
& D_{22} \frac{\partial^{2} \beta}{\partial y^{2}}+\left(D_{11}+D_{66}\right) \frac{\partial^{2} \alpha}{\partial x \partial y}+D_{66} \frac{\partial^{2} \beta}{\partial x^{2}}-A_{44}\left(\beta+\frac{\partial w}{\partial y}\right)=0 \\
& A_{55}\left(\frac{\partial \alpha}{\partial x}+\frac{\partial^{2} w}{\partial x^{2}}\right)+A_{44}\left(\frac{\partial \beta}{\partial y}+\frac{\partial^{2} w}{\partial y^{2}}\right)+p(x, y)=0
\end{aligned}
$$

\subsection{Solutions for simply supported plates}

Point load $F$ at coordinate location $x=u, y=v$ is modelled as a Fourier series Deformation trial solutions and assumed loading $q$ are [3]

$$
\begin{array}{ll}
w(x, y)=\sum_{m=1}^{\infty} \sum_{n=1}^{\infty} C_{\mathrm{mn}} \sin \left(\lambda_{\mathrm{m}} x\right) \sin \left(\lambda_{\mathrm{n}} y\right) & , \alpha(x, y)=\sum_{m=1}^{\infty} \sum_{n=1}^{\infty} A_{\mathrm{mn}} \cos \left(\lambda_{\mathrm{m}} x\right) \sin \left(\lambda_{\mathrm{n}} y\right) . \\
\beta(x, y)=\sum_{m=1}^{\infty} \sum_{n=1}^{\infty} B_{\mathrm{mn}} \sin \left(\lambda_{\mathrm{m}} x\right) \cos \left(\lambda_{\mathrm{n}} y\right) & , q(x, y)=\sum_{m=1}^{\infty} \sum_{n=1}^{\infty} a_{\mathrm{mn}} \sin \left(\lambda_{\mathrm{m}} x\right) \sin \left(\lambda_{\mathrm{n}} y\right)
\end{array}
$$




\subsection{Principal elastic modulus and thickness of substitute plate material}

Bending stiffness in axial direction of the substitute plate

$$
\begin{aligned}
& (E I)_{\text {plate }}=(E I)_{\text {side-plate }}+(E I)_{\text {tube }} \\
& D_{1} b=\frac{E_{1} h^{3}}{12\left(1-v_{12} v_{21}\right)} b^{\prime}=E I_{\mathrm{y}}+E I_{\text {side-plate }}=E \cdot \pi r^{3} t+E \frac{a^{\prime} c^{3}}{12} . \\
& E_{1}=E \quad, \quad b^{\prime}=D+a^{\prime} \quad, \quad r=\frac{1}{2}(D-t)
\end{aligned}
$$

Thus the substitute elastic modulus $E_{1}$ may be set equal to actual elastic modulus. The substitute plate wall thickness is obtained as $h=0.033 \mathrm{~m}$ by

$$
h=\left[12 \pi \frac{1}{8}(D-t)^{3} \frac{t}{b^{\prime}}+c^{3} \frac{a^{\prime}}{b^{\prime}}\right]^{\frac{1}{3}} .
$$

Here $D=0.052, t=0.0055, a^{\prime}=0.020, b^{\prime}=0.052+0.02=0.072$

\subsection{Transverse elastic modulus of substitute plate material}

Bending stiffness in transverse direction

$$
\begin{aligned}
& \left(E_{2} I_{2}\right)_{\text {plate }}=(E I)_{\text {steel side-plate }}, E_{2} \frac{h^{3}}{12}=E \frac{h_{\mathrm{st}}^{3}}{12} \\
& E_{2}=E\left(\frac{h_{\mathrm{st}}}{h}\right)^{3}=E u \approx 200000\left(\frac{5}{33}\right)^{3}=700 \mathrm{MPa} \rightarrow u=\left(\frac{h_{\mathrm{st}}}{h}\right)^{3}
\end{aligned}
$$

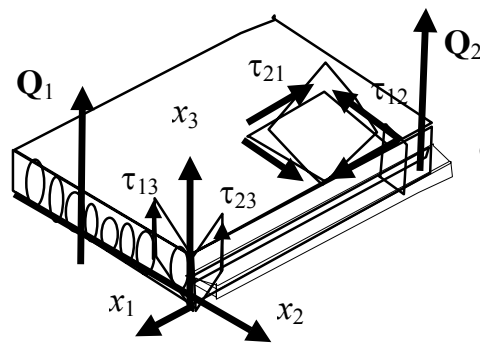

a)

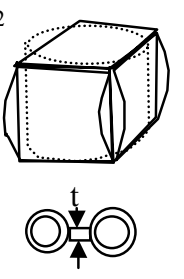

b)

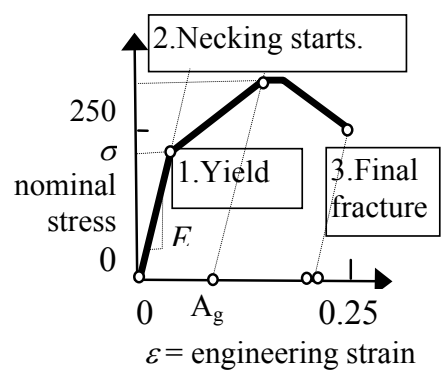

c)

Figure 4: Plate model basics. a) Stress resultants. b) Burst pressure model. c) Material model used is elastic-plastic work hardening model.

\subsection{Bending stress estimates}

First stiffness some matrix elements are needed 


$$
\begin{aligned}
& \frac{v_{21}}{E_{2}}=\frac{v_{12}}{E_{1}} \rightarrow \quad v_{\mathrm{TL}}=\frac{E_{\mathrm{T}}}{E_{\mathrm{L}}} v_{\mathrm{LT}} \approx \frac{700}{200000} 0.3 \\
& Q_{12}=\frac{v_{\mathrm{LT}} E_{\mathrm{T}}}{1-v_{\mathrm{LT}} v_{\mathrm{TL}}} \rightarrow=v u E \quad, \quad Q_{22}=\frac{E_{\mathrm{T}}}{1-v_{\mathrm{LT}} v_{\mathrm{TL}}}=u E
\end{aligned}
$$

The first terms of the series are used to get rough estimates

Maximum stress of the substitute plate in $y$ - transverse direction assuming point force load and maximum stress at the middle of the substitute plate

$$
\begin{gathered}
\sigma_{\mathrm{y}, \text { max }}=\left(Q_{12} \kappa_{\mathrm{x}, \max }+Q_{22} \kappa_{\mathrm{y}, \text { max }}\right)_{\max } \frac{1}{2} h=-\left(v E \frac{\pi}{a} a_{11} A_{\mathrm{L}}+r E \frac{\pi}{b} a_{11} B_{\mathrm{L}}\right)_{\text {max }} \frac{1}{2} h \cdot(18) \\
\sigma_{\mathrm{y}, \text { max }}=-\pi E a_{11}\left(v u \frac{1}{a} A_{\mathrm{L}}+r \frac{1}{b} B_{\mathrm{L}}\right) \frac{1}{2} h \quad, \quad \sigma_{\mathrm{y}, \text { max }, \mathrm{st}}=\sigma_{\mathrm{y}, \max }\left(\frac{h}{h_{\mathrm{st}}}\right)^{2} .
\end{gathered}
$$

The additional pressure was maximum at the explosion $0.005 \mathrm{MPa}$ caused by a small amount of water into inside from a leak. Ambient pressure is atmospheric $p_{\mathrm{a}}=0.1 \mathrm{MPa}$. Overpressure is $p_{o}=p / p_{\mathrm{a}}-1$. Now it is $(0.105 / 0.1-1)=0.05$. According fig. $3 \mathrm{c}$ this means at a distance of $5 \mathrm{~m}$ severe damage although the overpressure is decreased by a factor $k_{1}=0.5$. A reasonable assumption of even pressure decreases this further by $k_{2}=0.4$. Total reduction factor is $k_{\mathrm{r}}=0.2$. The bending stresses in transverse direction at the substitute plate is about $23 \mathrm{MPa} \cdot k_{\mathrm{r}}=4.6 \mathrm{MPa}$, at actual plate it is $k_{\mathrm{r}} \cdot 23 \cdot(33 / 5)^{2}$ or to about $200 \mathrm{MPa}$. The nominal UTS is about $440 \mathrm{MPa}$. These rough estimates show that a large risk for fracture is probable and also what are the governing parameters.

\section{Burst pressure of cylinders}

The vessel in not an isotropic cylinder but a rectangular orthotropic shell. Burst pressure of aluminium tubes [7].

$$
p^{\prime}=K \frac{2 t}{D-0.8 t} \sigma_{t} \rightarrow p=0.8 \frac{2 \cdot 0.0055 m}{7 m} 200 M P a=0.25, \quad K=0.73+0.33 \frac{\sigma_{\mathrm{y}}}{\sigma_{\mathrm{t}}} .
$$

where $p^{\prime}$ is burst pressure, $K$ is coefficient depending on strength ratio, $t$ is thickness, $D$ is outside diameter, $\sigma_{\mathrm{t}}$ is tensile strength of material in longitudinal direction $\sigma_{\mathrm{y}}$ is yield strength of material

\section{Finite element modeling}

\subsection{Geometry}

The geometry of the boiler wall and boundary conditions are presented in fig. 6 . Due to symmetry only $1 / 4-$ model is needed, fig. 3b. Main dimensions of the 1/4-model are $5000 \mathrm{~mm} \times 1500 \mathrm{~mm}$ (width $\mathrm{x}$ height). Boiler wall is made of 
tubes, diameter $52.0 \mathrm{~mm}$, wall $5.5 \mathrm{~mm}$ and flat plates, $20.0 \mathrm{~mm}$ x $5.0 \mathrm{~mm}$, assembled between the tubes with continuous welds.

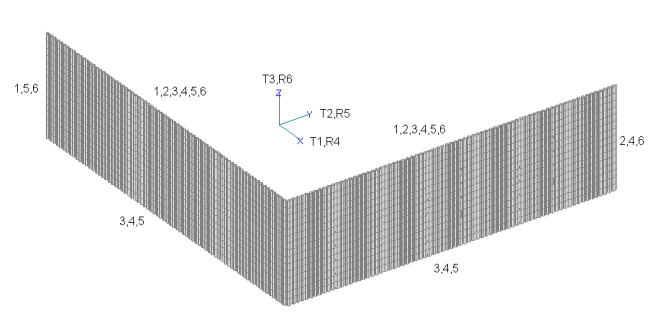

a)

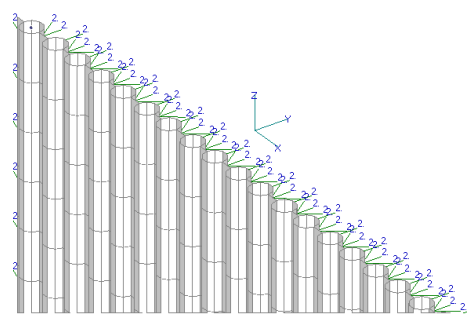

b)

Figure 5: Boiler wall. a) View with boundary conditions. b) Pressure loading.

\subsection{Material properties}

The material model used is elastic-plastic work hardening model is shown in fig. 5c. Material properties are isotropic. They have the same elastic and strength properties $(E, G$ and $v)$ in all three $\mathrm{x}, \mathrm{y}$ and $\mathrm{z}$ coordinate directions. In nonlinear modeling only two additional material properties are needed: the yield strength and tangent modulus. Material properties in FE- models are shown in table 1.

Table 1: $\quad$ Material properties.

\begin{tabular}{|l|l|}
\hline Description & Carbon steel. Typical properties \\
\hline Elasticity factor $E[\mathrm{MPa}]$ & 200000 \\
\hline Tangent modulus $E_{\mathrm{t}}[\mathrm{MPa}]$ & 1045 \\
\hline Poisson's factor $v[-]$ & 0.3 \\
\hline Yield strength $R_{\mathrm{p} 0.2}\left[\mathrm{~N} / \mathrm{mm}^{2}\right]$ & 217 \\
\hline Tensile strength $R_{\mathrm{m}}\left[\mathrm{N} / \mathrm{mm}^{2}\right]$ & 445 \\
\hline
\end{tabular}

\subsection{Boundary conditions}

Model is located on the top of the boiler, fig. 3b. It is assumed that the corner of the roof and wall is rigid. So translation downwards is insignificant. Symmetry boundary conditions are shown in fig. 6 .

\subsection{Loads and element properties}

Only inner pressure acts in the boiler. In the linear static analysis the value of the pressure is $5000 \mathrm{~Pa}$. In nonlinear analysis pressure is $0.2 \mathrm{MPa}$. This value is chosen to be so large that ultimate tensile strength will be reached. In the FE- model only one type of element is used, since it will fully satisfy requirements accuracy and solution speed. The element type was CQUADR. It is quadrilateral, isoparametric membrane-bending plate element with vertex rotations having 6 degrees of freedom per node. 


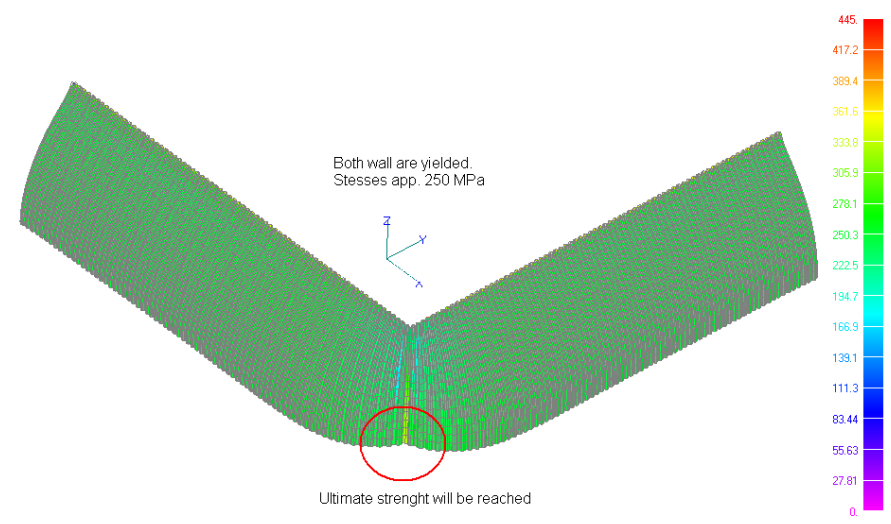

a)

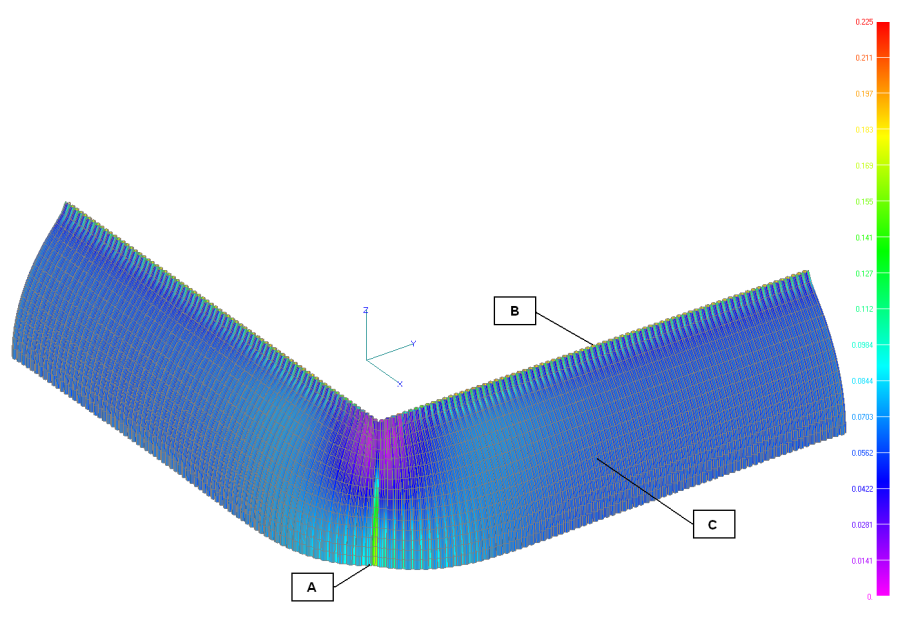

b)

Figure 6: Nonlinear analysis results. a) Von Mises stresses have risen over yield strength 217 to a mean value of about 250. b) Deformed form of the wall showing contours of plastic strain. Von Mises stress and the corresponding plastic strain at structure A: (396, 0.153), B: $(433,0.215), C(265,0.1)$.

\subsection{Results of linear and nonlinear analysis}

In the linear static analysis displacements and stresses are linearly related to the applied forces. Linear static analysis is done to find out maximum stress level and maximum displacement. Nonlinear analysis results in fig. 6 show how at the critical locations plastic areas grow and due to work-hardening the yield strength approaches ultimate strength. Calculated stress will exceed it since there is no termination in the material model. Results show optimal locations for fail safe joints between walls for preventing extensive damage. 


\section{Conclusions}

The following conclusions can be drawn.

- Loading is a complex pressure force impact on the plate. An equivalent static peak model gives conservative enough results.

- Fail safe joints are needed to protect from larger damage.

- Recovery boilers are essential parts in paper processing industry for burning chemicals into more ecological form and for obtaining steam.

- The goal of reliable service life without major damages causing costly process interruptions can be obtained by condition monitoring, intermediate repair and another one is to use preventive design focusing on welds.

- Analytical orthotropic plate model is physically based and reveals factors FEM analysis with plastic or also fracturing models reveal effectively and reliably the stresses and deformations at desired pressure scenarios. One advantage of nonlinear analysis is that it reveals risk areas close to ultimate tensile strength of new tubes with no corrosion. Another advantage is that risk of fracture due to local thinning of the tubes can be studied by these virtual methods. Use of these methods increases safety and reliability of operation.

\section{References}

[1] Agarwal, B.D. \& Broutman L.J. Analysis and performance of fibre composites, John Wiley \& Sons, Inc.1990.

[2] Barbero, E.J.Introduction to composite materials design, Taylor \& Francis, 1999.

[3] Swanson, S.R., Introduction to design and analysis with advanced composite materials, Prentice Hall, New Jersey, Philadelphia, 1997.

[4] MSC Nastran FEM program.

[5] LS-DYNA Version 950, university licence version, Theoretical manual, Livermore Software Technology Corporation, Livermore.

[6] Kurttila, H., Isentropic Exergy and Pressure of the Shock Wave Caused by the Explosion of a Pressure Vessel, PhD Thesis, 2003, Lappeenranta University of Technology, ISBN 951-764-813-8.

[7] M L Sharp, Behaviour and design of aluminium structures, McGraw,, 1993 